\title{
Condensin Compacts DNA in 15nm steps and Requires FACT for Extrusion on Chromatin
}

Swathi Sudhakar ${ }^{1,2}$, Gemma LM Fisher ${ }^{3}$, Pilar Gutierrez-Escribano ${ }^{3}$, Jonay Garcia-Luis ${ }^{3}$, Christopher Cawood ${ }^{3}$, Luis Aragon ${ }^{3 *}$ and David S Rueda ${ }^{1,2^{*}}$

The authors have withdrawn this manuscript after detecting issues with two of the figures in the manuscript. Therefore, the authors do not wish this work to be cited as a reference. If you have any questions, please contact the corresponding authors.

* Corresponding authors. Email: luis.aragon@1ms.mrc.ac.uk; david.rueda@imperial.ac.uk 